\title{
Theoretical and Practical Considerations in Colo-Rectal Diverticulosis Complicated with Multiple Sigmoido-Recto-Vesical Fistulas
}

Călin Molnar ${ }^{1 *}$, Ciprian Silaghi², Adrian Chiujdea ${ }^{3}$, Ecaterina Daniela Dobru ${ }^{4}$, Ciprian Rosca ${ }^{2}$, Cosmin Nicolescu ${ }^{5}$, Victor losif Neagoe ${ }^{2}$, Vlad $^{2}$ Olimpiu Butiurca ${ }^{2}$, Claudiu Varlam Molnar ${ }^{6}$ and Constantin Copotoiu ${ }^{11}$

${ }^{1}$ University of Medicine and Pharmacy Târgu Mureș, Department M5 - First Surgical Unit, Emergency County Hospital Târgu Mures, Romania

${ }^{2}$ First Surgical Unit, Emergency County Hospital, Târgu Mureș, Romania

${ }^{3}$ Department of Urology, Emergency County Hospital, Târgu Mureș, Romania

${ }^{4}$ Department of Gastroenterology, Emergency County Hospital, Târgu Mureș, Romania

${ }^{5}$ University of Medicine and Pharmacy Târgu Mures, Department of Anatomy, Târgu Mures, Romania

${ }^{6}$ University of Medicine and Pharmacy Târgu Mureș, Department M5 - First Unit of Obstetrics and Gynecology Emergency County Hospital, Târgu Mureș, Romania

\begin{abstract}
Although there is a complete anatomical separation between urinary and digestive tract, in certain pathological conditions, the direct proximity between the bladder and the sigmoid colon allows the development of entero-vesical fistulas. Colic diverticulosis is the second leading cause of entero-vesical fistulas, after malignancy. Usually, the enterovesical fistula is unique, on a single bowel segment; rarely is multiple, involving different intestinal segments. We present the case of a 41 years old man, with a double fistula: sigmoido-vesical and recto-vesical, respectively. The diagnosis was challenging despite the clinical aspect included pneumaturia and fecaluria. A particular symptom was sexual dysfunction. CT scan and a pelvic MRI revealed the two fistula colo-vesical and recto-vesical. A recto-sigmoid resection with subperitoneal colo-rectal anastomosis and partial cystectomy were performed with uneventful postoperative recovery. CONCLUSION: The multiple entero-vesical fistulas developed on a single intestinal segment are extremely rare, and, to our knowledge this is the only case reported in the literature. The management is challenging, and in our opinion the resection with anastomosis and partial cystectomy is the best choice.
\end{abstract}

Keywords: Colic diverticulosis; Diverticulitis; Entero-vesical fistula; Multiple Colo-vesical fistula

\section{Introducere}

Fistulele entero-vezicale au fost descrise pentru prima dată în urmă cu peste două milenii de catre Rufus și Ephesus [1], dar diverticuloza colică a fost semnalată ca o entitate patologică doar în secolul al XVIIIlea [2]. Etiologia acestora este variată: malignitățile (20\%), diverticulita și afectiunile inflamatorii ale intestinului, traumatisme (accidentale, ingestia de oase, corpi străini), iatrogenii (radioterapie, intervenții în micul bazin și regiunile herniare, explorări endoscopice) [1,3]. Anatomic, fistulele entero-vezicale se împart în colo-vezicale, rectovezicale, ileo-vezicale și apendiculo-vezicale [1]. Respectând legile fizicii elementare, apariția unor fistule multiple pe același segment intestinal sau pe segmente aflate unul în imediata continuitate a celuilalt sunt aproape imposibile. Sunt citate în literatura fistule duble (ileo-colo-vezicală, apendico-ileo-vezicală) [4]. Nu am găsit publicaţii care să certifice prezența unei fistule colo-recto-vezicale, în care partenerii digestivi implicați să presupună structuri parietale și gradiente presionale similare.

Patognomonice pentru fistula entero-vezicală sunt din punct de vedere clinic fecaluria și/sau pneumaturia (63\%) [1], diagnosticul anatomo-topografic fiind dificil (CT cu contrast, urografia micțională, cistoscopia cu contrast și IRM). Tratamentul chirurgical cu morbiditatea [5] și mortalitatea cea mai scăzută este cel într-un singur timp, presupunând rezecția colică cu anastomoză și cistectomie parțială cu cistorafie [1].

\section{Prezentare de caz}

Prezentăm cazul unui pacient de sex masculin, în vârstă de 41 ani, din mediul urban, internat în clinica Chirurgie I din cadrul Spitalului Clinic Județean de Urgență Târgu Mureș în condiții de programare. La internare pacientul acuză subfebrilitate $\left(37,5-38^{\circ} \mathrm{C}\right)$, frisonete, fecalurie și pneumaturie, tenesme vezicale, tulburări de dinamica sexuală. Istoricul afecțiunii se întinde pe o perioada de 4 ani, pacientul prezentând fecalurie și pneumaturie intermitentă, infecții urinare repetate cu uroculturi pozitive pentru Escherichia coli, urmând la indicația urologului cure repetate de antibioterapie "țintite" argumentate prin antibiograme. Evoluția bolii este trenanta, cu perioade scurte asimptomatice (maxim 7-10 zile), după care constată reinstalarea simptomatologiei urinare, însoțită de frisonete, subfebrilitate și tulburări psiho-sexuale.

Se prezintă în mai multe servicii private de gastroenterologie și urologie, unde în urma examinărilor clinice și paraclinice (colonoscopie endoscopică, colonoscopie virtuală, cistoscopie) este etichetat și "tratat" cu prostatită recidivantă și ulterior chiar "operat" pentru boala hemoroidală. Având în vedere persistența simptomatologiei, apariția unor tulburări de dinamică sexuală cu implicații în viața de cuplu, pacientul este îndrumat la Clinica de Urologie a Spitalului Clinic Județean Târgu Mureș unde se practică CT cu contrast (Figura 1) și urografie micțională și cistografie (Figura 2) care ridică suspiciunea unei fistule "în supapă" între domul vezical și colonul sigmoid.

*Corresponding author: Călin Molnar, MD, PhD, First Surgical Unit, Emergency County Hospital Târgu Mureș Str. N. Grigorescu 31/12, 540136, Târgu Mureș, Mureș, Romania, Tel: +40 (0) 7226966 10; Fax: +40 (0) 7226966 10; E-mail: molnar.calin@yahoo.com

Received January 09, 2014; Accepted March 13, 2014; Published September 20, 2014

Citation: Molnar C, Silaghi C, Chiujdea A, Dobru ED, Rosca C, et al. Theoretical and Practical Considerations in Colo-Rectal Diverticulosis Complicated with Multiple Sigmoido-Recto-Vesical Fistulas. Journal of Surgery [Jurnalul de chirurgie] 2014; 10(2): 183-186 [article in Romanian] DOI: 10.7438/1584-9341-10-2-16

Copyright: ( 2014 Molnar C, et al. This is an open-access article distributed under the terms of the Creative Commons Attribution License, which permits unrestricted use, distribution, and reproduction in any medium, provided the original author and source are credited. 


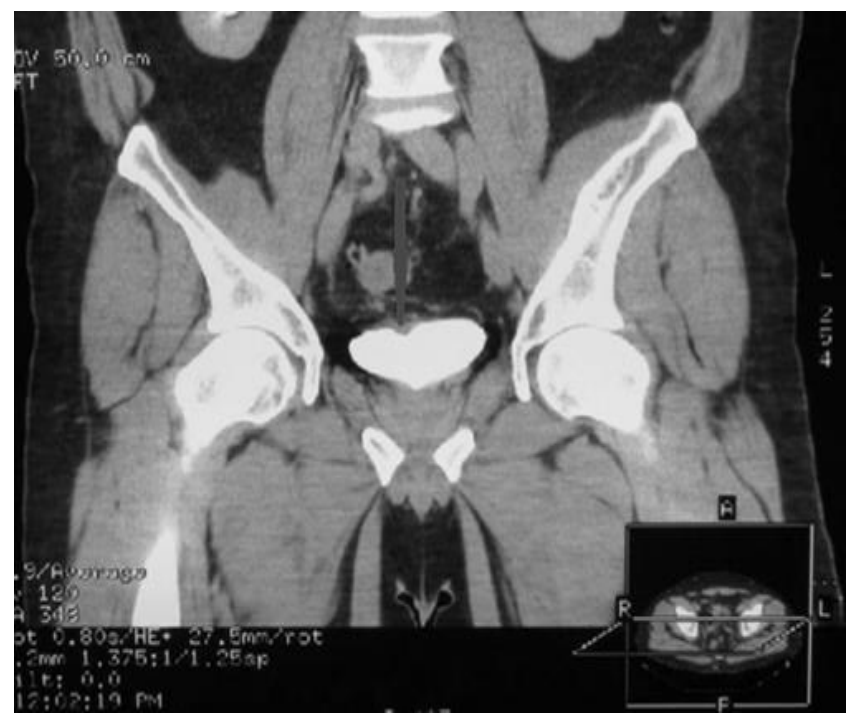

Figura 1: Computer tomografie: obiectivarea fistulei superioare sigmoidovezicale.

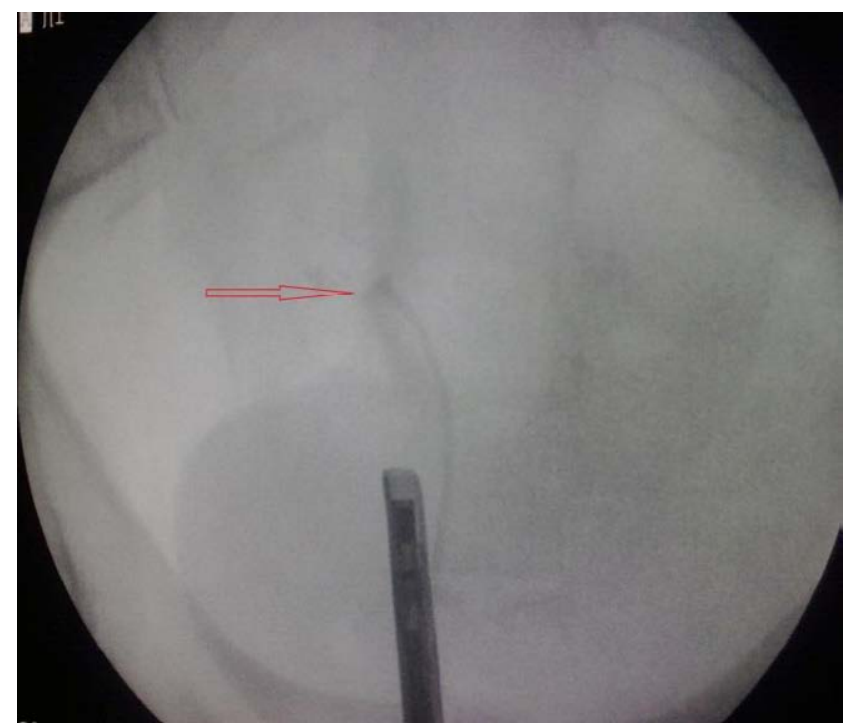

Figura 2: Cistografie: evidențierea orificiului fistulos.

Consultul chirurgical ridică suspiciunea unui dublu traiect fistulos, de aceea se recurge la IRM care semnalează prezența celui de-al doilea orificiu la nivelul rectului superior, în vecinătatea joncțiunii ureterovezicale drepte, obiectivat ulterior printr-o recto-sigmoidoscopie (Figura 3 and 4). În momentul internării pacientul prezintă o stare generală bună, subfebril, fără fecalurie manifestă, dar cu urocultura pozitivă pentru Escherichia coli, leucocitoză $\left(13.000 / \mathrm{mm}^{3}\right)$, restul parametrilor biologici fiind în limite normale.

După o pregătire preoperatorie adecvată (locală antimicrobiană și mecanică anterogradă) se intervine chirurgical sub anestezie generală printr-o laparotomie mediană. Se descoperă prezența unui sindrom aderențial inflamator secundar unei diverticulite, care acolează și ultima ansă ileală, aceasta putând fi însă eliberată (Figura 5).

La nivelul buclei inferioare a sigmoidului aderentă la domul vezical precum și la nivelul rectului superior (sub repliul peritoneal) în vecinătatea implantării ureterului drept în vezica se constată cele două fistule "etajate", sigmoido- și respectiv, recto-vezicală (Figura 6).
Se eliberează colonul și rectul și vezica cu verificarea instrumentară a orificiilor fistuloase.

Se exclud endoluminal alte leziuni sincrone și se procedează apoi, după expunerea ureterelor pelvine bilateral, la rezecția rectosigmoidiană de la nivelul joncțiunii descendentului cu sigma până la 2-3 cm subperitoneal. Se verifică endoluminal existența altor orificii

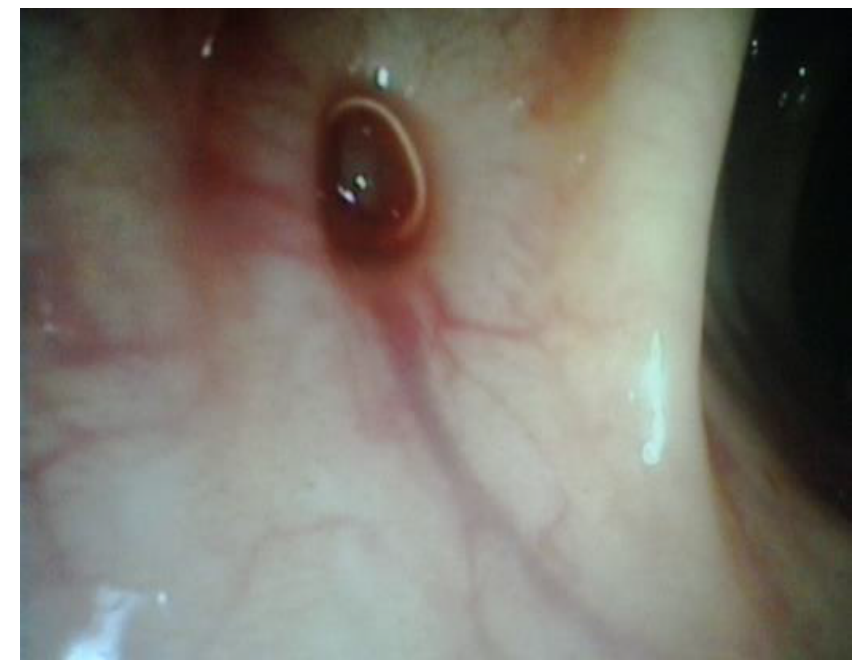

Figura 3: Colonoscopia: fistula superioară (sigmoido-vezicală).

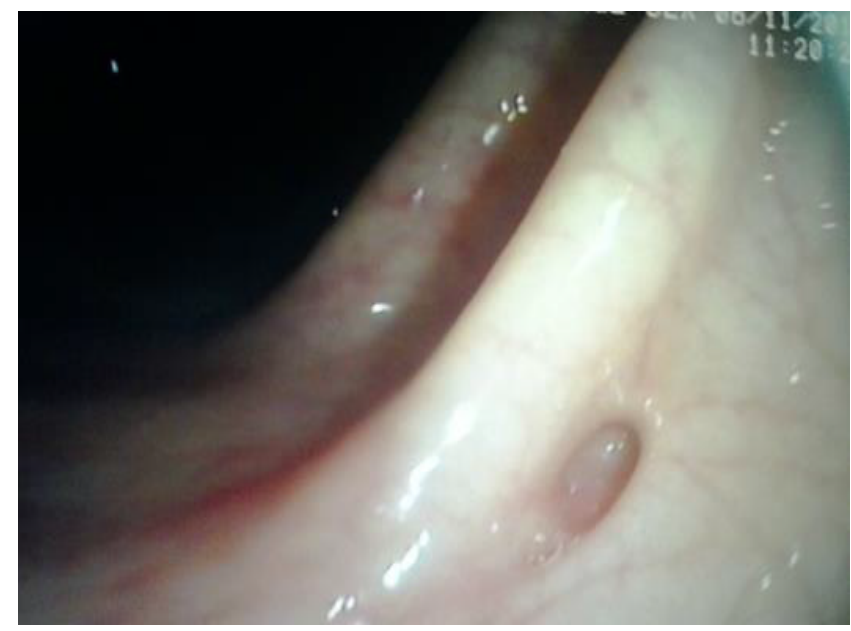

Figura 4: Colonoscopia: fistula inferioară (recto-vezicală).

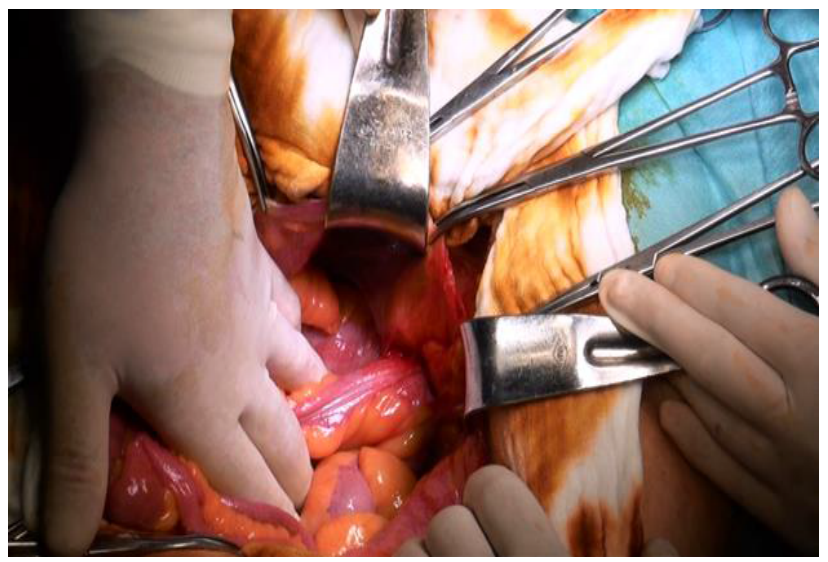

Figura 5: Aspectul procesului inflamator local. 


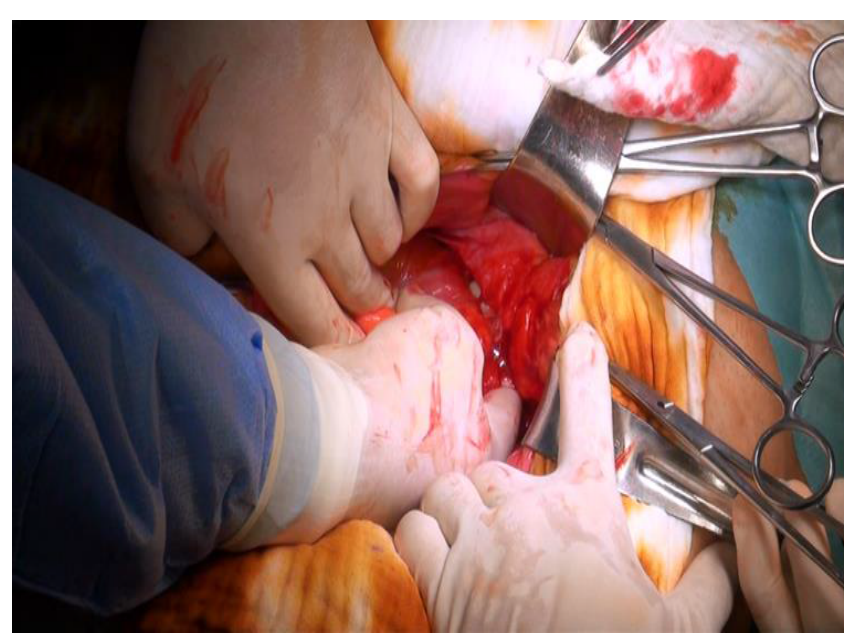

Figura 6: Evidențierea introperatorie a fistulei superioare și suprimarea prin digitoclazie a traiectului fistulos sigmoido-vezical.

fistuloase și apoi se realizează o cistectomie parțială cu cistorafie per primam monoplan cu fire lent resorbabile și lăsarea "à demeurre" a unei sonde Foley de $14 \mathrm{Ch}$.

Continuitatea tubului digestiv se restabilește printr-o anastomoză colo-rectală termino-terminală monoplan. Se verifică etanșeitatea cistorafiei cu albastru de metilen instilat pe sonda vezicală și după toaleta cavității peritoneale se plasează un tub de dren decliv, perianastomotic exteriorizat în fosa iliaca dreapta prin contra-incizie. Evoluția postoperatorie a fost favorabilă, cu externare în ziua a 14-a, plaga vindecată per primam și uroculturile postoperatorii repetate fiind negative. La 21 zile post-operator se suprimă sonda urinară, iar 2 luni post-operator pacientul este asimptomatic, fără acuze digestive și urinare, re-inserat social și familial. Examenul histopatologic al pieselor operatorii confirmă diverticuloza acolo-rectală și a infirmat malignitatea.

\section{Discuții}

Din punct de vedere clinic diverticuloza colică poate fi simptomatică sau asimptomatică. Prevalența diverticulozei și a diverticulitei este strâns corelată cu vârsta (aproximativ 30\% la indivizii de peste 50 de ani și $66 \%$ la populația peste 85 ani) [6]. Există o distribuție anatomică diferită a bolii diverticulare în funcție de arealul geografic al pacienților; alimentația săracă în reziduuri crește riscul apariției afecțiunii, dieta săracă în fibre crescând incidenta bolii [7]. Este demonstrată statistic implicarea mai frecventă a colonului stâng în țările vestice (99\%) și a colonului drept în țările asiatice $[7,8]$. Migrația populațională și împrumutarea dietelor vestice în țările asiatice au crescut incidenta diverticulozei colonului stâng și în această zonă geografică[8]. Diverticulita este cea mai frecventă complicație a diverticulozei și apare în peste $90 \%$ din cazuri pe colonul sigmoid $[9,10]$. Din totalul pacienților spitalizați cu diagnosticul de diverticulită acută un număr important (15-30\%) necesită tratament chirurgical [9]; unii autori recomandă colectomiile după al doilea episod de recurență [9] alții doar după al patrulea [11]. În cazul pacienților imunodeprimati chirurgia este indicată după primul episod [9]. Young-Fadok semnalează apariția fistulelor entero-vezicale în $2 \%$ din cazuri [12], iar dintre cei ce reclamă tratament chirurgical pentru boala diverticulară, aproximativ $20 \%$ prezintă fistule, $65 \%$ dintre acestea fiind colo-vezicale [12]. Dintre afecțiunile inflamatorii ce duc la apariția fistulelor entero-vezicale, diverticulita este responsabilă în 50-70\% din cazuri. Alături de aceasta sunt citate: boala Crohn (10\%), diverticulita Meckel, coccidiomicoza genito-urinară, actinomicoza pelvină și boala Fabry. Etiologia inflamatorie este secundară însă, pe primul loc situându-se neoplasmele (colo-rectal, vezico-urinar, col uterin, prostată, ovarian, limfomul intestinului subțire). Cauzele iatrogene sunt secundare intervențiilor în micul bazin (prostatectomii, histerectomii, cura laparoscopică a herniilor). Radioterapia poate duce la enterită radică cu posibilitatea apariției fistulelor chiar la intervale lungi (ani) după iradiere. Ingestia unor corpi străini (oase de pui sau de pește) poate duce în mod excepțional la dezvoltarea unor comunicări patologice între intestin și vezica urinară [1]. Privind mecanismul apariției fistulelor entero-vezicale în cadrul bolii diverticulare, factorul inflamator și relația de vecinătate a organelor sunt decisive. S-a constatat o prevalență a sexului masculin comparativ cu cel feminin $(4,1 / 1)$, uterul interpus între colorect și vezica urinară constituind un factor protector [1].

Legea gradientelor presionale enunțata de Laplace [9] și apariția țesuturilor inflamatorii peri-diverticulare pot sugera două mecanisme de apariție a fistulelor entero-vezicale: extensia directă a diverticulului inflamat dinspre partenerul digestiv cu perforația acestuia în vezică și cel de al doilea, mai plauzibil în diverticulita acută, eroziunea parietală a partenerului urinar de către un abces diverticular $[13,14]$ prin "foaierul intermediar" descris de către Chavannaz [15]. De altfel gradientul presional dintre cele două sisteme cavitare și apariția acestei comunicări anormale, explică specificitatea și sensibilitatea simptomelor majore (pneumaturia $71,4 \%$ din cazuri, fecaluria $51 \%$ din cazuri) [8]. Pe de altă parte, frecvența simptomelor urinare (polakiurie, disurie, tenesme vezicale, hematurie) și absența aproape completă a micturiei sesizabilă de pacienți la defecație, amână nejustificat diagnosticul etiologic al acestor bolnavi [13], etichetați și tratați timp îndelungat în mod eronat $\mathrm{cu}$ infecții urinare recidivate, boala hemoroidală, prostatite cronice, fapt constatat și în cazul clinic prezentat.

Țesutul inflamator periorificial poate constitui o clapetă ce explică parțial caracterul intermitent al infecțiilor urinare recurente, tipice unui mecanism "cu supapă". În observația noastră existența unui dublu orificiu fistulos pe segmente digestive aflate în imediata vecinătate și continuitate (sigmoid și rect superior) a fost dificil de diagnosticat. Suspiciunea unor fistule "etajate" a justificat reexplorarea suplimentară a pacientului (colonoscopie totală, cistografie micțională, cistoscopie cu contrast, CT cu contrast) care au permis în final obiectivarea a doua traiecte fistuloase separate: sigmoido-vezical și recto-vezical. Examinarea paraclinică cu cea mai mare sensibilitate şi specificitate este computer tomografia $\mathrm{cu}$ administrare de contrast (40-100\%) [12,16]. Aceasta obiectivează traiectul fistulos în condițiile în care acesta este activ, certificată prin prezenta aerului în vezică [1]. Pneumaturia însă poate fi și expresia unei infecții cu clostridii sau a unei candidoze genito-urinare [1], de aceea excluderea acestora prin examenul sumar al urinei și urocultura este obligatorie. În cazul nostru singurul germene obiectivat a fost Escherichia coli. Autorii japonezi arată importanță limitată a altor examinări (testul clinic cu ingestia de semințe de mac, irigografia $45 \%$, cistoscopia $23,2 \%$, cistografia retrograda $11,6 \%$, rezonanță magnetică 3,2\%) [1]. Rolul imagisticii prin rezonanță magnetică nucleară este important în cazurile cu fistule multiple. Localizarea anatomică, aspectul țesuturilor din jur, morfologia traiectelor fistuloase au implicație în alegerea procedeului chirurgical $[13,17]$. În ultimii ani colonoscopia virtuală pare să capete un rol important la pacienții ce nu tolerează explorări invazive [18]. Tratamentul diverticulitei colo-rectale complicat cu fistulă este prin excelență chirurgical, închiderea spontană a fistulei fiind excepțională. W.J. Mayo descrie în 1907 trei procedee chirurgicale adresate atât colonului cât și vezicii urinare [19]. Indicațiile tipului de intervenție trebuie individualizate în funcție de statusul biologic al pacientului (vârsta, prezența sepsisului local și general, starea de nutriție) dar și de performanță anastezico-chirurgicală a echipei. În condițiile unui pacient tânăr, fără patologie asociată, operația într-un singur timp (rezecție colică cu anastomoza per primum fără colostomie de protecție) este cea mai utilizată (70\%) [20]. Pacienților cu condiții mai precare (vârstnici, tarați) vor beneficia de rezecție cu anastomoză și 
colostomie în amonte, sau procedeul Hartmann. Intervenția în trei timpi este astăzi adresată doar pacienților cu risc anestezico-chirurcigal crescut, cu abcese peri-diverticulare și semne de impregnare septică, colostomia fiind primul gest chirurgical asociat însă unei terapii intensive energice [21].

În observația noastră s-a practicat operația într-un singur timp, pregătirea generală și locală a colonului fiind posibile. Fiind vorba de o fistulă dublă "etajată", s-a efectuat rezecție recto-sigmoidiană cu anastomoză colo-rectală termino-terminală monoplan, fără colostomie. Pentru a preveni recidiva și a permite ridicarea orificiului inferior, intervenția a respectat ghidul Societății Americane de Chirurgie a Cancerului Colonic și Rectal (2006), conform căruia marginea de rezecție distală trebuie să coboare sub locul în care tenia colică atinge rectul superior [22].

Atitudinea asupra vezicii urinare este diferențiată. În situația în care orificiul fistulos nu este găsit intraoperator se poate recurge la plombaj cu epiploon a zonei vezicale implicate în procesul inflamator și plasarea unei sonde Foley pentru 1-2 săptămâni. Dacă fistula este evidențiată sutura acesteia poate fi opțiunea de ales [23]. Uneori, datorită procesului aderențial se recurge la cistotomie diagnostică [8]. Cistectomia parțială până în țesut sănătos, menajând implantările vezico-ureterale, cu cistografie per primam și sondaj vezical "à demeurre" 2-3 săptămâni este astăzi cea mai acceptată $[1,8]$. În situația fistulelor duble, sutura este iluzorie; de aceea noi am optat pentru rezecție parțială a vezicii cu sutură per primam monoplan și plasarea unei sonde Foley ce permite și controlul intraoperator al etanșeității acesteia, folosind instilarea de albastru de metilen.

\section{Concluzii}

Posibilitatea unei fistule colo-recto-vezicale etajate în diverticulita acolo-rectală este o entitate rară, nemaifiind citată în literatură. Pneumaturia și fecaluria sunt patognomonice; în condițiile unui pacient tânăr, netarat, cu perturbări ale vieții sexuale și modificări psihosomatice datorate unei afecțiuni non-neoplazice, examinările și reexaminările imagistice și endoscopice sunt cele justificate, nicidecum tratamentele "simptomatice". Intervenția chirurgicală într-un singur timp (rezecția recto-sigmoidiană cu anastomoză colo-rectală concomitent cu cistectomia parțială urmată de cistorafie) pare a fi soluția de ales.

\section{Conflict de interese}

Autorii nu declară niciun conflict de interese.

\section{Bibliografie}

1. Mukherjee $T$, Sirsat $R$ (2006) Colo-vesical fistula presenting as urinary trac infection. J Assoc Physicians India 54: 488-490.

2. Levy SB, Fitts WT Jr, Lench JB (1967) Surgical treatment of diverticular disease of the colon: evaluation of an eleven-year period. Ann Surg 166: 947-954.
3. Nishimori H, Hirata K, Fukui R, Sasaki M, Yasoshima T, et al. (2003) Vesicoileosigmoidal fistula caused by diverticulitis: report of a case and literature review in Japan. J Korean Med Sci 18: 433-436.

4. Kawamura YJ, Sugamata Y, Yoshino K, Abo Y, Nara S, et al. (1998) Appendicoileo-vesical fistula. J Gastroenterol 33: 868-871.

5. Tang YZ, Booth TC, Swallow D, Shahabuddin K, Thomas M, et al. (2012) Imaging features of colovesical fistulae on MRI. Br J Radiol 85: 1371-1375.

6. Larsson PA (1997) [Diverticulitis is increasing among the elderly. Significant cause of morbidity and mortality]. Lakartidningen 94: 3837-3840, 3842.

7. Chan CC, Lo KK, Chung EC, Lo SS, Hon TY (1998) Colonic diverticulosis in Hong Kong: distribution pattern and clinical significance. Clin Radiol 53: 842844.

8. Yang HY, Sun WY, Lee TG, Lee SJ (2011) A case of colovesical fistula induced by sigmoid diverticulitis. J Korean Soc Coloproctol 27: 94-98.

9. Ravinder K. Annamaneni, NanaKram Agrarwal (2005) "Gastrointestinal Surgery in older adults". Practical gastroenterology.. USA

10. Lupascu C, Vlad N, Andronic D, Nistor A, Trifan A, et al. (2005) Fistula sigmoidovezical - caz clinic. Jurnalul de Chirurgie, lasi; $1:$ 419-422.

11. Salem L, Veenstra DL, Sullivan SD, Flum DR (2004) The timing of elective colectomy in diverticulitis: a decision analysis. J Am Coll Surg 199: 904-912.

12. Mileski WJ, Joehl RJ, Rege RV, Nahrwold DL (1987) One-stage resection and anastomosis in the management of colovesical fistula. Am J Surg 153: 75-79.

13. Melchior S, Cudovic D, Jones J, Thomas C, Gillitzer R, et al. (2009) Diagnosis and surgical management of colovesical fistulas due to sigmoid diverticulitis. $J$ Urol 182: 978-982.

14. Najjar SF, Jamal MK, Savas JF, Miller TA (2004) The spectrum of colovesical fistula and diagnostic paradigm. Am J Surg 188: 617-621.

15. Lockhart-Mummery HE (1958) Vesico-intestinal fistula. Proc R Soc Med 51 1032-1036.

16. Amendola MA, Agha FP, Dent TL, Amendola BE, Shirazi KK (1984) Detection of occult colovesical fistula by the Bourne test. AJR Am J Roentgenol 142: 715718

17. Ravichandran S, Ahmed HU, Matanhelia SS, Dobson M (2008) Is there a role for magnetic resonance imaging in diagnosing colovesical fistulas? Urology 72 : 832-837.

18. Nadır I, Ozın Y, Kiliç ZM, Oğuz D, Ulker A, et al. (2011) Colovesical fistula as a complication of colonic diverticulosis: diagnosis with virtual colonoscopy. Turk J Gastroenterol 22: 86-88.

19. Mayo WJ, Wilson LB, Giffin HZ 1907 Acquired diverticulitis of the large intestine. Surg Gynec Obstet; 5: 8.

20. Wedell J, Banzhaf G, Chaoui R, Fischer R, Reichmann J (1997) Surgica management of complicated colonic diverticulitis. Br J Surg 84: 380-383.

21. Vasilevsky CA, Belliveau P, Trudel JL, Stein BL, Gordon PH (1998) Fistulas complicating diverticulitis. Int J Colorectal Dis 13: 57-60.

22. Rafferty J, Shellito P, Hyman NH, Buie WD (2006) Standards Committee of American Society of Colon and Rectal Surgeons. Practice parameters for sigmoid diverticulitis. Dis Colon Rectum 49: 939-944.

23. Ferguson GG, Lee EW, Hunt SR, Ridley CH, Brandes SB (2008) Management of the bladder during surgical treatment of enterovesical fistulas from benign bowel disease. J Am Coll Surg 207: 569-572. 